\title{
O FILHO PRÓDIGO: MIGRAÇÃO E IDENTIDADE EM ESSA TERRA, DE ANTÔNIO TORRES'
}

\author{
THE PRODIGAL SON: MIGRATION AND IDENTITY IN \\ ANTÔNIO TORRES'S ESSA TERRA
}

\section{Lucas Mateus Mariz de Andrade ${ }^{2}$ André Tessaro Pelinser ${ }^{3}$}

\begin{abstract}
Resumo: Na crítica literária brasileira, o regionalismo tem sido visto como símbolo de passadismo, pitoresco, ruralismo, inferioridade. O emprego, por parte dos autores, de temas, imagens e motivos regionais tem sido associado a uma visão negativa sobre a qualidade da obra, tornando-a incompatível com a ideia - por si só problemática - de "universal". A percepção do regionalismo como literatura de baixa qualidade se perpetuou ao longo do tempo e tem feito com que autores contemporâneos cujas obras se filiam à tradição regionalista neguem esta designação. O objetivo deste trabalho é identificar como essa problemática se relaciona à criação literária de um desses autores, Antônio Torres, verificando como se manifestam elementos do regionalismo em Essa terra, de 1976. Para tanto, analisamos como a obra apresenta o contraste entre centro e periferia, evidenciado pela polarização entre campo e cidade, e buscamos compreender como esses aspectosse relacionam às ideias de migração, identidade e pertencimento. Além disso, a forma como o próprio autor lida com a afirmação ou a negação do regionalismo presente em seus livros também faz parte desta análise, a partir do exame de entrevistas concedidas pelo autor sobre o tema.

Palavras-chave: Regionalismo; migração; identidade; Essa terra; Antônio Torres.
\end{abstract}

\begin{abstract}
In Brazilian literary criticism, regionalism has been seen as a symbol of veneration for the past, picturesque, ruralism, inferiority. The use by the authors of regional themes, images and motifs has been associated with a negative view of the quality of the work, making it incompatible with the idea - by itself problematic - of "universal". The perception of regionalism as low quality literature has perpetuated over time and has caused contemporary authors whose works affiliate with the regionalist tradition to deny this designation. The aim of this paper is to identify how this problem is related to the literary creation of one of these authors, Antônio Torres, verifying how elements of regionalism manifest themselves in Essa terra, published in 1976. For that purpose, we analyze how the work introduces the contrast between center and periphery, evidenced by the polarization between countryside and city, and we seek to understand how these aspects relate to the ideas of migration, identity and belonging. In addition, the way the author himself deals with the affirmation or denial of regionalism present in his books is also part of this analysis, based on the examination of interviews granted by the author on the subject.
\end{abstract}

Keywords:Regionalism; migration; identity; Essa terra; Antônio Torres.

\section{Introdução}

A percepção da identidade está frequentemente ligada às noções de pertencimento e de localismo. Segundo Paulo da Luz Moreira, observa-se nos Estados Unidos, no Brasil e no México

\footnotetext{
${ }^{1}$ Este trabalho é resultado de pesquisa de Iniciação Científica financiada pelo Programa Institucional de Bolsas de Iniciação Científica da Universidade Federal do Rio Grande do Norte (PIBIC/UFRN).

${ }^{2}$ Licenciado em Letras pela Universidade Federal do Rio Grande do Norte.

${ }^{3}$ Professor de Literatura Brasileira na Universidade Federal do Rio Grande do Norte. Doutor em Estudos Literários pela Universidade Federal de Minas Gerais.
} 
um tipo de ficção localista caracterizada por manifestar certa afeição pelas margens da modernização, mostrando as mudanças acarretadas por processos modernizadores e como há um comprometimento artístico com essa realidade. Na perspectiva de Moreira, para o autor filiado ao modernismo localista, o espaço não é mera ambientação, uma vez que as suas vivências são decisivas dentro dos seus respectivos processos de criação. (MOREIRA, 2012, p.15-36)

No entanto, a concepção de localismo defendida pelo autor vai de encontro à percepção vigente em parcela representativa da crítica literária brasileira. Moreira apresenta um olhar voltado para a estética da narrativa moderna, argumentando que ela favorece a quebra da polarização entre campo e cidade - nela, o campo não é simplesmente um lugar atrasado, assim como a cidade não é um lugar inequivocamente avançado. No cenário literário brasileiro, porém, convencionou-se a ideia de que, na ficção, o regional e o rural são símbolos de fixação da realidade, isto é, mera cópia documental de dado contexto.

O problema tem sua origem no século XIX, mais precisamente com o Romantismo. A partir dos ideais que alimentaram a busca por um instinto de nacionalidade, a nossa literatura começa a se utilizar cada vez mais de uma mimese caracterizada pela descrição da realidade em seu processo de criação. O estilo literário da época entendia que era necessário encontrar e representar os símbolos da brasilidade. (cf. SANTINI, 2014, p. 117-118) A esse procedimento, Machado de Assis argumenta, em Notícia da atual literatura brasileira: instinto de nacionalidade, que o utilizamos pois não somos capazes de produzir um romance de análise psicológica, tão necessário frente aos problemas da sociedade da época, talvez "porque seja esta casta de obras ainda incompatível com nossa adolescência literária.” (ASSIS, 2008, p. 1206)

Embora Machado de Assis não aborde o problema do regionalismo, que a bem da verdade até então sequer estava sistematizado, sua afirmação reverbera e é assimilada pela crítica literária posterior, que passa a entender que tanto o Romantismo quanto o regionalismo literário utilizavam um processo de mimese demasiadamente descritivo. No século XX, a ideia de que este último era símbolo de rural, de arcaico e de fixação da realidade encontra terreno para se firmar nos pensamentos de Antonio Candido e Lúcia Miguel Pereira. Esta associa o regionalismo literário a "simples fixação de tipos, costumes e linguagem local" (PEREIRA, 1988, p. 175).

Apreendido de diversos modos ao longo do tempo, tal pensamento faz, por sua vez, com que autores contemporâneos como Antônio Torres tenham algum receio ao serem rotulados como escritores regionalistas:

O que acha de ser chamado de escritor regionalista?

O que leva a isso é o meu título mais forte até hoje, que é o Essa terra (1976) [...] Mas eu não sou um sambista de uma nota só, quer dizer, luto para não ser um sambista de uma nota só. Passeio também por ambientes urbanos [...] Logo, essa impressão de que eu sou um escritor regionalista faz sentido até um certo ponto. Quem leu só o Essa terra ou a trilogia pode ficar com essa impressão. Mas se buscar mais do meu trabalho verá que não é bem assim. (TORRES, 2010, s/p, grifo nosso)

Nota-se uma preocupação do autor ao ser questionado sobre a associação ao rótulo de escritor regionalista. Tal atitude pode estar relacionada à definição reducionista consolidada por anos de crítica literária, uma vez que, definindo o regionalismo literário daquela forma, ela estaria criando no imaginário coletivo a ideia de uma literatura puramente documental, restritamente mimética, ou seja, retirando o caráter literário das obras associadas à tradição regionalista. Quando Torres responde que também passeia por ambientes urbanos, nota-se certa intensificação no receio de que sua obra seja associada ao ambiente rural, supostamente arcaico, "onde os hábitos e estilos de vida se diferenciem dos que imprime a civilização niveladora" (PEREIRA, 1988, p. 175). Convencionou-se acreditar que é também desta mesma civilização que se retira a referência de qualidade literária, isto é, ela dita o que é a boa e a má literatura, pois não está à margem, mas no centro, no ambiente urbano ao qual Torres faz referência, o que justificaria em parte o receio expresso em sua resposta.

https://periodicos.unifap.br/index.php/letras

Macapá, v. 9, n. 2, $2^{\circ}$ sem., 2019 
Assim, torna-se importante compreender como se deu o processo de construção da visão da crítica literária sobre a tradição regionalista, a fim de que possamos entender as modulações desta tradição na contemporaneidade.

\section{Migração, pertencimento e identidade na obra}

No que diz respeito a Essa terra, de Antônio Torres, o pertencimento identitário está bastante presente em toda a narrativa, relacionando-se intimamente com a migração e o espaço regional, e não se limita a um único personagem. Consigo, este mesmo pensamento suscita outras problemáticas, como a migração de Nelo, ainda na juventude:

Nelo descobriu que queria ir embora no dia em que viu os homens do jipe. Estava com 17 anos. Ele iria passar mais três anos para se despregar do cós das calças de papai. Três anos sonhando todas as noites com a fala e as roupas daqueles bancários [...] (TORRES, 1991, p.18)

Nelo é o filho mais velho de um casal de moradores da pequena cidade de Junco, interior da Bahia, e é o retrato do filho ideal antes e, principalmente, depois que dá início ao seu processo de migração. Trata-se de uma família desestruturada, em que se percebem a pobreza e os conflitos internos entre o pai e a mãe. A migração do personagem, aos 20 anos, é apresentada ao longo da narrativa como fruto do anseio pela melhoria de vida oferecida pelo centro do país, em contraste com as dificuldades enfrentadas pelos habitantes do Junco, essa zona periférica, distante da modernização ou da suposta “civilização niveladora”,para usar a expressão de Lúcia Miguel Pereira.

O processo migratório do personagem em questão levanta uma problemática já apontada por José Clemente Pozenato. Ao discutir a ideia de região segundo os estudos de Pierre Bourdieu, o autor conclui que “esse estigma que o 'centro' imprime sobre a 'província' repercute em todas as representações que se façam de região" e que, "no plano das representações culturais, o estigma estabelece que a 'província' é um mundo acanhado, estreito, incapaz de transpor as próprias fronteiras" (POZENATO, 2003, p. 156). É este mundo acanhado que os moradores do Junco gostariam de deixar para trás. O mundo que fica em uma região provinciana ao norte do centro econômico e social. A visão comum de que o sul representa os ideais econômicos e sociais faz com que a região do Junco seja vista como província. O mundo ideal, rico e próspero é o mundo do sul:

\footnotetext{
Onde esses braços se encontravam? Dentro do ônibus, em cima dos caminhões. Descendo. Para o sul de Alagoinhas, para o sul de Feira de Santana, para o sul da cidade da Bahia, para o sul de Itabuna e Ilhéus, para o sul de São Paulo-Paraná, para o sul de Marília, para o sul de Londrina, para o sul do Brasil. A sorte estava no sul, para onde todos iam, para onde ele tava indo. Uma vez, em Feira de Santana, ficou parado na rodoviária, durante uma manhã inteira. Uma zanzação sem começo nem fim, um entra e sai de formigueiro vivo. Ficou embasbacado: - Se aqui não é nem bem os princípios do sul, imagine como não será o resto. (TORRES, 1991, p. 62)
}

Para além desse mundo ideal, o que vemos, por outro lado, são processos migratórios falidos. As ações de vários personagens, em momentos específicos da narrativa, comprovam tal afirmação. A própria migração do primogênito não é bem detalhada na narrativa, uma vez que não há referências precisas sobre os mais de 20 anos que Nelo vive em São Paulo. O que sabemos é que, em meio às muitas dificuldades, a migração não foi para Nelo o que ele esperava. Constituiu família, conseguiu empregos, foi demitido, virou alcoólatra, vagou sem rumo pelas ruas de São Paulo, foi espancado. Apesar de todos esses problemas, duas imagens eram alimentadas no imaginário da sua cidade natal: o filho pródigo vive e a migração para o sul era uma realidade promissora.

Ao que tudo indica, essas duas imagens sobreviviam por dois motivos: Nelo se recusava a 
voltar para o Junco e assumir que seu processo migratório tinha sido um fracasso, ou, no mínimo, não era como acreditava ser; e ele continuava, não se sabe como, mandando mensalmente uma quantia em dinheiro para os seus pais. Assim, todos acreditavam que Nelo era "o exemplo vivo de que a nossa terra também podia gerar grandes homens" (TORRES, 1991, p.14). A ideia de pertencimento a uma região associada a esse personagem talvez seja uma das mais problemáticas apresentadas em toda a narrativa. Entre novas vivências e alguns reencontros, Nelo mostra-se angustiado e entra em uma profunda crise de identidade:

Aqui, no meio da rua. Na grande capital. Dinheiro, dinheiro, dinheiro. Cresce logo, menino, pra você ir para São Paulo. Aqui vivi e morri um pouco todos os dias. No meio da fumaça, no meio do dinheiro. Não sei se fico ou se volto. (TORRES, 1991, p.47, grifo nosso)

Apesar de entender que o seu processo migratório foi conflituoso e não gerou o que ele almejava, Nelo preferiu sofrer sozinho durante parte dos mais de 20 anos em que viveu em São Paulo, ao invés de voltar para o Junco. Percebe-se, portanto, um indivíduo desenraizado das suas origens, que prefere sofrer a voltar para o seu lar, lugar em que provavelmente teria apoio da sua família, não precisando mais enfrentar as dificuldades sozinho. Assumindo uma atitude comum a alguém que enfrenta problemas constantes após um processo migratório infrutífero, Nelo regressa, afinal, ao Junco. No entanto, o retorno não se apresenta como solução para o indivíduo em crise, visto que sua volta é imediatamente seguida de seu suicídio. Partindo do pressuposto de que os ideais de pertencimento não estão presentes em nenhum momento na mente do personagem, como explicar a necessidade de retorno ao lugar em que nasceu para só então cometer o suicídio?

Como podemos perceber, a relação estabelecida entre o mundo supostamente ideal do sul, os moradores da cidade do Junco e os ideais de pertencimento e identidade é, em suma, conflituosa. A migração do primogênito também desperta os conflitos migratórios atrelados à perda de identidade e pertencimento na vida da sua família. Totonhim, irmão de Nelo e narrador de Essa terra, nos mostra que "Foi contigo que as mudanças começaram, porque foste o primeiro a descobrir a estrada [...] O brilho de tua estrela iluminava as nossas noites mortas" (TORRES, 1991, p.102).

As mudanças acarretadas pela descoberta da estrada não demoram a reverberar na matriarca da família, em quem se percebe que a vontade de buscar melhorias em uma região mais desenvolvida é maior do que os laços de identidade que a prendem a "essa terra", o Junco. Ao enviar as filhas para um convento em Feira de Santana, na tentativa de tirar as meninas da vida sofrida que ela julgava existir no Junco, recebe a notícia de que a expulsão delas da ordem é iminente. De pronto, para evitar o retorno das filhas para a cidade natal e contra a vontade do próprio marido, decide também ir para Feira de Santana: "Elas não voltam. Eu é que vou pra lá. E vocês vêm depois. A decisão não ia ser fácil. Motivo: papai. Como sempre.” (TORRES, 1991, p. 102103)

Como resultado desse processo, o fracasso. Percebe-se, pois, que os ideais de pertencimento ao lugar, isto é, ao Junco, são refletidos de forma negativa nas ações da personagem. Viver na nova cidade não era nada melhor do que na anterior, mas a matriarca da família não recuava, assim como Nelo o fez em São Paulo. Voltar seria reconhecer que falhou e que a vida no Junco, a cidade provinciana e sem perspectivas, seria melhor do que a vida no mundo ideal do sul:

Acabamos todos nos arranchando numa casinha pobre de uma rua pobre de um bairro pobre, sem luz, sem água, sem esgoto, sem banheiro. Mamãe alugou a casa fiando-se no dinheiro que mandavas todo mês e, quando atrasavas a remessa, era um deus nos acuda. Vivíamos permanentemente debaixo do medo de sermos postos na rua. [...] Mamãe se matava de trabalbar, penso que era para não dar o braço a torcer, coisa de orgulbo pessoal, medo do fracasso. (TORRES, 1991, p.103, grifo nosso)

O processo migratório desencadeado pela figura de Nelo reverbera, ainda, de modo con-

https://periodicos.unifap.br/index.php/letras

Macapá, v. 9, n. 2, $2^{\circ}$ sem., 2019 
traditório, nas decisões do restante da família. É esse o caso do patriarca, único indivíduo que demonstra amor inequívoco pela sua terra natal e que, mesmo com todo o sofrimento, é o último da família a abandonar o Junco. Quando se vê sozinho e falido, totalmente desestruturado pelas ações advindas de um processo de modernização representado pela figura dos bancos na pequena região do Junco, deixa a sua cidade e migra para Feira de Santana. Ao chegar, encontra um lugar em notável frenesi. Era outro símbolo de progresso. Feira de Santana estava no sul e a sorte estava lá:

Uma vez, em Feira de Santana, ficou parado na rodoviária, durante uma manhã inteira. Uma zanzação sem começo nem fim, um entra e sai de formigueiro vivo. Ficou embasbacado: - Se aqui não é nem bem os princípios do sul, imagine como não será o resto (TORRES, 1991, p. 62).

A vida desse personagem é bastante singular: é o único a demonstrar maior amor à terra natal, maior vínculo de pertencimento a ela, mas, em meio ao abandono e aos problemas financeiros, cede ao desejo comum de migrar para o sul. O pertencimento à terra seria maior que o sofrimento gerado por ela? Não raramente, o personagem se admira com o progresso do sul, com as perspectivas de mudança causadas pela modernização, mas as suas raízes afloram em cada momento em que o sul se impõe como o lugar de modernidade, lugar em que uma roça não é, digamos, o seu símbolo mais representativo. Apesar disso, para o personagem, não sabemos se por mera falta de conhecimento ou por puro amor ao ofício de trabalhador rural, o desejo de ir para São Paulo não é, nem de longe, parecido com o do seu primogênito: Nelo queria fugir da vida rural, ao passo que seu pai via na região sul uma nova chance de recomeçar a sua plantação, a sua amada roça, não importando se ele seria tão somente um empregado ou dono das terras:

Não, não era para Feira de Santana que queria ir. A mulher e os filhos que the restaram que se ajeitassem sozinhos. Homem que é homem não aceita restos. Iria mesmo era para São Paulo ou Paraná, terras boas, onde certamente encontraria uma roça para tomar conta, como se fosse dono. (TORRES, 1991, p.49)

Nessa mesma linha, nota-se o amor do personagem pela terra nas últimas páginas da obra, quando o seu filho do meio, Totonhim, lhe informa que vai se desfazer de tudo e partir para São Paulo, assim como o fez o seu primeiro filho:

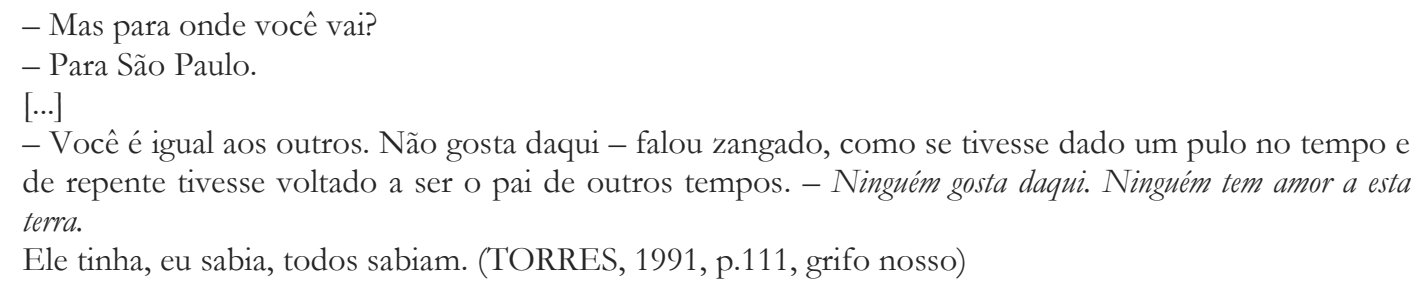

Aqui, temos Totonhim, irmão de Nelo e principal narrador da história, como já sabemos. A migração, os ideais de pertencimento e de identidade atrelados à figura dele são tão problemáticos quanto os do seu irmão. Enquanto este último, desde o momento da sua partida, mantevese presente no imaginário dos moradores do Junco como aquele que prosperou na vida, o primeiro cresceu à sua sombra, sempre marginalizado pela importância do filho pródigo, como a sua mãe nos mostra: "Tomara eu tivesse mais um filho igual a ele. Bastava um. Nelo, Nelo, Nelo." (TORRES, 1991, p.20) Essa indiferença problematizada nos aponta para um filho angustiado, aflito, sem perspectivas de um amor materno: "Éramos doze, contando uma irmã que já morreu. Só ele contava. Nelo, Nelo, Nelo. - Bastava mais um.” (TORRES, 1991, p.20)

A migração de Totonhim, inicialmente forçada pela figura de sua mãe quando esta o tirou do Junco e o levou para Feira de Santana ainda criança, numa tentativa frustrada de fugir do atraso que seria morar em uma região rural, isto é, afastada do centro, atinge o seu ponto máximo 
quando, já adulto, afirma para o pai que decide abandonar emprego, família, amigos e ir para São Paulo, tal como Nelo. O que tem o potencial de causar estranheza em um leitor mais (ou será menos?) atento é o fato de que Totonhim foi o único dos irmãos que teve contato com um Nelo frustrado com o seu processo migratório. O Nelo rico e próspero que permeava o imaginário do povo do Junco não era o mesmo que estava ali, e somente

Totonhim e o boticário da cidade, Zé da Botica, sabiam disso. Ao narrar o episódio em que o farmacêutico pede uma contribuição para a construção de um ginásio, Totonhim mostra que ele e o dono da farmácia haviam descoberto a verdade sobre o grande Nelo:

—Zé, vou precisar da sua ajuda. Quero uns remedinhos.

O farmacêutico, por trás do balcão, de pé, conferia a lista das pessoas que deveriam contribuir para a fundação do ginásio e ficou feliz por ver que ainda faltava um nome.

$[\cdots]$

- Tome esta nota agora. Depois eu dou mais.

— Tudo ajuda — disse Zé, que ainda não sabia a verdade: aquele era o sen último dinheiro, o que restava daquilo que se pensava ser uma verdadeira fortuna.

Então ele mostrou a receita e fez a encomenda. E assim como, tempos antes, os exames de sangue e fezes o puseram a nu perante si mesmo, agora tinha o seu corpo inteiramente devassado pelo farmacêtico: os remédios eram para siffilis e esquistossomose. $\mathrm{O}$ outro pedido era o segredo que Zé da Botica, um homem sério e, a bem dizer, seu primo, deveria guardar para o resto da vida.

- Zé - eu já estava trancando a casa e saindo, atrás dele. - Eu pago a conta. Espere até o fim do mês. Assim que en receber da Prefeitura, en the pago.

— Está certo — disse o farmacêutico. — Não vou contar nada para o seu pai.

Desci para a venda. (TORRES, 1991, p.36-37,grifos nossos)

Totalmente consciente de como era a vida do seu irmão, dos malefícios advindos da migração para São Paulo e dos vários legados negativos que a suposta modernidade do sul trouxe para a sua vida, a exemplo da dispersão da sua família e da falência do seu pai, e para os demais moradores do Junco, o que se esperava era que Totonhim não escolhesse traçar um caminho parecido - eis o motivo daquele provável estranhamento causado no leitor. Ora, no sul, Nelo angariou doenças e decepções. Depois de mais de vinte anos, o dinheiro que levou para o Junco tampouco deu para comprar os remédios de que necessitava, deixando a dívida para o seu irmão.

Sabendo disso, como explicar o fato de uma pessoa abandonar a sua cidade, o seu emprego, a sua vida e enveredar por um caminho tortuoso? O que faz Totonhim relatar que quer ir para o tão moderno sul? Ao atentarmos mais diretamente para a vida desse personagem, deparamo-nos com uma possível resposta: a sua terra não tinha nada a oferecer, a sua família o desprezava. Preterido pela família, que agora já se encontra totalmente fragmentada - isto é, a mãe internada em um manicômio, o pai em outra cidade, a maior parte dos irmãos longe e a descoberta de que a estrela iluminadora das suas noites fúnebres, vulgo Nelo, além de ter morrido, não era e nunca foi o que se esperava que fosse -, São Paulo torna-se uma alternativa viável, senão a única vislumbrada.

\section{Migração, pertencimento e identidade para além da obra}

A personagem Nelo representa, em suma, um migrante que sai do interior do Junco para a grande cidade de São Paulo. A antiga região do Junco é, hoje, a cidade de Sátiro Dias, em que nasceu Antônio Torres. Tendo cuidado para não incorrer em simples biografismo, neste caso em especial não é inoportuno identificar a relação existente entre o lugar de origem do escritor e as possíveis nuances dentro de sua obra. Isto configura a discussão sobre os lugares biográficos e sua constituição como espaço umbilical na obra de cada autor. No que tange a este assunto, Stüben argumenta: 
Lugares da biografia de escritores possuem com frequência uma relação existencial direta que se encontra em suas obras, como reflexo do reino da experiência real ou como contramundo utópico. O papel do lugar de origem, de residência ou de exílio, para a identidade de um autor, dificilmente pode ser superestimado. Sua visão do mundo, seu rico acervo de experiências, suas mais profundas emoções - tudo o que de mais precioso entra em sua obra está baseado em sua percepção do ambiente, que é decisivamente constituído pelas condições topográficas. Para aquele que escreve, mesmo no caso de uma mudança forçada de lugar, a terra natal permanece inalienável e experimenta sua constituição literária, muitas vezes, somente através da retrospectiva. (STÜBEN, 2013, p. 39)

Como sustenta Stüben, é certo que o lugar de origem do autor não deve ser simplesmente subestimado. É crucial analisar as relações existentes entre o autor e a sua obra para que possamos compreender alguns aspectos desta última. Entendendo esta relação, podemos compreender os ideais de pertencimento que permeiam a vida dos personagens de Essa terra. Torres, em uma entrevista concedida à revista Navegações e intitulada “As 'pessoas' na obra de Antônio Torres", ao ser questionado sobre a presença de personagens considerados rurais em sua obra, responde que tal escolha foi por simples facilidade em evocar algo que ele já viveu: "Sempre que recorro a um contra-campo para São Paulo ou Rio de Janeiro, fica mais fácil evocar o meio rural em torno do povoado da minha infância [...]".(VENTURA, 2010, p.165) Nota-se que o posicionamento do autor vai ao encontro do de Stüben.

$\mathrm{Na}$ mesma entrevista, Torres afirma que o Junco não é mais o mesmo de antes e que ele também está inserido no seu outro romance, intitulado Um táxi para Viena d'Áustria. Um ponto problemático, entretanto, está presente na última afirmação do escritor. Há algo parecido com uma necessidade de enfatizar que este último romance citado é "um romance urbaníssimo, pósmoderno etc. e tal." (VENTURA, 2010, p.207) A primeira afirmação de Antônio Torres dá a entender que a escolha dos personagens e do ambiente que eles permeiam, de fato, tem relação com o seu lugar de origem. Não há qualquer negação neste sentido. A segunda nos mostra certa preocupação com a necessidade de associar sua obra a um espaço urbano, central e supostamente modernizado, um espaço tradicionalmente benquisto pela crítica literária brasileira.

As pessoas, isto é, os personagens de Essa terra, estão, de fato, imersos no imaginário de Torres antes mesmo de ele pensar em escrever. Tudo faz parte das suas vivências como indivíduo inserido em um meio social e o reflexo delas não pode ser diminuído ou negado. Adotemos a perspectiva do urbano e imaginemos Torres como um autor que jamais viveu em um lugar como o Junco e sequer conheceu pessoas cujas personalidades se associem às de Totonhim, sua mãe, Nelo ou o louco Alcino, moradores daquele ambiente supostamente rural, pitoresco, regional: será que aquele autor, desprovido das vivências comuns ao povo e aos lugares de Essa terra, construiria, na mesma proporção, obra de igual qualidade?

Em Introdução à literatura no Brasil (2001, p. 2002), Afrânio Coutinho, após definirque "toda obra de arte é regional quando tem por pano de fundo alguma região em particular ou parece germinar intimamente desse fundo", numa tentativa de separar o que ele próprio chama de simples localismo do largo regionalismo literário, afirma, ainda,que "um romance pode ser localizado numa cidade e tratar de problema universal", umavez que a "localização é incidental". Trata-se de afirmação problemática, uma vez que reduz a importância do lugar na construção da obra, relegando-oa simples pano de fundo, como se a localização da obra, o espaço, a ambientação fosse meramente incidental. Com base nisso, seria possível inferir que sim, que um autor desconhecedor do espaço, da história, do imaginário do Junco conseguiria construir obra de igual qualidade. Temos, pois, um problema, já que estaríamos descartando todo um conjunto de vivências indispensáveis à construção dos sentidosda obra, pois elas não passariam de simples pano de fundo de um texto cuja localização seria incidental.

Em Essa terra, as respectivas vivências, a cultura do povo do Junco, os problemas de cada morador que, de certa forma, apontam para algo maior, para problemas comuns a pessoas de várias partes do mundo, carregam grande potencial de significação. A dor de Totonhim, ao ser relegado à sombra de seu irmão, é tão singular quanto o momento em que a sua mãe surta ao ter 
consciência da morte do seu filho mais velho. Assim como os conflitos existentes nesses personagens, o espaço compartilhado por eles não pode ser desconsiderado na narrativa. Ao mesmo tempo em que desconsiderar tais elementos seria um equívoco, reconhecê-los parece contrariar, no imaginário de autores e estudiosos contemporâneos, pressupostos críticos consolidados por décadas de história literária, uma vez que implicaria aceitar a relevância de espaços e culturas periféricos historicamente associados à restrição das possibilidades expressivas. Ademais, reconhecendo aqueles elementos, seus nomes estariam associados, na visão desta mesma crítica, a uma tradição literária que abarca obras de baixa qualidade: o Regionalismo.

Essa associação gera problemas nada desprezíveis aos escritores contemporâneos. Em entrevista concedida ao Jornal A Tarde, em junho de 2001, podemos perceber em Antônio Torrescerto desejo de não associar sua obra a um título como o de regional. Ao ser perguntado se, assim como os personagens do seu livro, ele se considera um retirante, o autor responde que a sua trajetória de retirante plasmou o seu próprio estilo de escrita literária e afetou a construção do seu imaginário, a partir da sua saída da terra natal. Porém, finaliza com a ideia de que, apesar daquela ligação com a terra existir, ele possui um caráter diferenciado de outros autores localistas e a sua obra mais representativa, Essa terra "não é regional, no pé da letra. Por isso, talvez, ele [o livro] seja cada vez mais apreciado no exterior." (TORRES, 2001, s/p)

A fala de Torres suscita questionamentos sobre o regional e o universal: não ser regional seria, ao que parece, o principal motivo de essa obra receber apreço no exterior. Se for regional, a obra parece estar limitada por fronteiras, jamais podendo ultrapassá-las. Nove anos depois, em uma segunda entrevista ao mesmo jornal, quando questionado diretamente sobre o que pensa de ser considerado um autor regionalista, Antônio Torres afirma que o que leva a isso é o seu título mais forte até aquele momento, Essa terra. Na mesma resposta, percebe-se mais do que uma simples divergência entre afirmações atuais e passadas, nota-se o desejo do autor de mostrar que não é, em suas próprias palavras, um "sambista de uma nota só", visto que passeia também por ambientes urbanos. Logo, a impressão de que ele é um escritor regionalista "faz sentido até um certo ponto. Quem leu só o Essa terra ou a trilogia pode ficar com essa impressão. Mas se buscar mais do meu trabalho verá que não é bem assim.” (TORRES, 2010, s/p).

Sem aderir ao título de regional, a partir da análise de Essa terra e de livros como Um táxi para Viena D'Áustria, como nos revela o próprio Torres em algumas entrevistas, constatamos que as experiências vividas por ele estão refletidas em sua escrita. A utilização delas na sua obra aponta para uma ideia de pertencimento ao seu lugar de origem, bem como para um indivíduo que não está perdido, isto é, não está sem vínculo identitário. Em entrevista concedida a Raphael Montes, apresentador do programa Trilha de Letras, da TV Brasil, levada ao ar em 15 de maio de 2018, podemos depreender em Antônio Torres preocupação com certo descaso dos leitores frente a obras nacionais. Para o entrevistado, percebe-se que o público nacional está mais interessado, nos últimos tempos, em ler o que na entrevista é chamado de literatura de consumo estrangeira, best-sellers. Para o autor, como o Brasil sequer faz parte do imaginário global, acaba por não fazer parte do imaginário brasileiro: é esse o ponto que o preocupa. Em sua fala, destaca ainda que, por mais que seja um autor traduzido para vários países e que viaje pelo mundo, ele quer o imaginário daqui, quer o leitor brasileiro.

Toda essa preocupação aponta igualmente para uma ideia de pertencimento ao lugar de origem. Portanto, temos em Torres uma representação antitética do personagem Nelo, uma vez que este volta para o Junco não movido por algum ideal de pertencimento ao lugar, mas por não ter outra opção melhor. O seu retorno revela alguém desprovido de vínculos e, como vimos, desemboca no suicídio, uma vez que, ao regressar, confirma que não possui nenhuma relação de pertencimento ao lugar, o que resulta em um desenraizamento existencial do indivíduo. Ao ser questionado sobre esse tema, na mesma entrevista concedida ao jornalista Carlos Ribeiro, do Jornal A Tarde, em 11 de junho de 2001, Antônio Torres corrobora o que afirmamos anteriormente com a seguinte resposta: "A questão resume-se no seguinte: talvez o homem que troca o seu

https://periodicos.unifap.br/index.php/letras

Macapá, v. 9, n. 2, $2^{\circ}$ sem., 2019 
lugar por outro perca o seu lugar e não conquiste o outro.” (TORRES, 2001, s/p)

\section{Considerações finais}

Após o término da pesquisa, é possível confirmarmos algumas hipóteses levantadas inicialmente. Percebe-se, pois, que há inúmeras reverberações do regionalismo na obra de Antônio Torres. O espaço, as vivências, os problemas e as relações sociais dos indivíduos representados em Essa terra inserem a obra em uma tradição regionalista com modulações próprias da contemporaneidade. Isso significa dizer que, ao lidar com o espaço e seus habitantes, por exemplo, aquele autor contemporâneo não o faz de maneira utópica ou programática, como já foi feito no passado, mas ainda assim a sua obra lida com todo um imaginário característico de uma tradição literária. As imagens criadas, os espaços, a linguagem, os topoi literários estão intrinsicamente vinculados a ela.

Apesar disso, temos a confirmação de que a visão problemática de parte da crítica literária construída em mais de meio século a respeito do Regionalismo, de fato, percorreu o tempo e chegou até autores contemporâneos, fazendo com que suas maneirasde lidar com a vinculação da sua obra ao rótulo de regionalista sejam, em determinados momentos, contraditórias. Podemos ver as marcas disso nos posicionamentos críticos presentes nas entrevistas concedidas por Antônio Torres. É interessante perceber como, em um dos casos, o autor não recusa terminantemente o rótulo, mas apenas indica que há mais faces em sua obra, enquanto em outro esboça posição mais assertivae procura desvincular-se dessa corrente literária. Isto é, ao ser convocado a abordar o problema do regional, suas posições são, por vezes, conflitantes, o que é natural em vista do histórico da questão.

Ante a comprovação da continuidade da tradição regionalista e dos problemas persistentes nela, há a necessidade de aprofundarmos os estudos sobre o tema, de discutirmos mais sobre ele e, principalmente, a respeito das suas modulações na contemporaneidade, compreendendo que o problema não está na simples existência de uma corrente, de uma tradição literária, mas sim na ideia de seguirmos atribuindo a ela valores negativos, isto é, utilizando-a como elemento balizador da qualidade estético-literária: se a obra é bem realizada, estaria necessariamente impedida de vincular-se ao regionalismo. Como nos aponta Chiappini (1994, p. 701), "há mais mistérios no regionalismo do que pretende a nossa vã pressa de ser modernos."

\section{Referências}

ASSIS, Machado de. Notícia da atual literatura brasileira: instinto de nacionalidade. In:

Obra completa, em quatro volumes: volume III. 2. ed. Rio de Janeiro: Nova Aguilar, 2008. p. 1203 1211.

BRASIL, Tv. Especial Antônio Torres / Programa completo. 2018. (27m 32s). Entrevista concedida a Raphael Montes, no programa Trilha de Letras. Disponível em: <https://www.youtube.com/ watch?v=mpxej8J4I70>. Acesso em: 10 jul. 2018.

CHIAPPINI, Ligia. Velha praga?Regionalismo literário brasileiro. In: PIZARRO, Ana (org.). América latina: palavra, literatura e cultura. São Paulo: Memorial; Campinas: UNICAMP, 1994. p. 659-701.

COUTINHO, Afrânio. Introdução à literatura no Brasil. 17. ed. Rio de Janeiro: Bertrand Brasil, 2001. MOREIRA, Paulo. Modernismo localista das Américas: os contos de Faulkner, Guimarães Rosa e Rulfo. Belo Horizonte: Editora UFMG, 2012.

PEREIRA, Lúcia Miguel. História da literatura brasileira: prosa de ficção: de 1870 a 1920. Belo Horizonte: Itatiaia; São Paulo: Editora da Universidade de São Paulo, 1988.

POZENATO, José Clemente. Processos culturais: reflexões sobre a dinâmica cultural. Caxias do Sul: Educs, 2003. 
STÜBEN, Jens. Literatura regional e literatura na região. In: ARENDT, J. C.; NEUMANN, G. R. (Org.). Regionalismus - regionalismos: subsídios para um novo debate. Caxias do Sul: Educs, 2013. p. 37-73.

TORRES, Antônio. Essa Terra. São Paulo: Editora Ática, 1991.

TORRES, Antônio. Não sou sambista de uma nota só. Entrevista concedida a Diego Damasceno. Jornal A Tarde, Salvador, 19 set. 2010. Revista Muito, s/p. Disponível em: $<$ http://www.antoniotorres.com.br/entrevista12.html>. Acesso em: 26 mai. 2019.

TORRES, Antônio. Sempre me coloquei ao lado dos oprimidos. Entrevista concedida a Carlos Ribeiro. Jornal A Tarde, Salvador, 11 jun. 2001. Disponível em: <http://www.antoniotorres.com. br/entrevista13.html> Acesso em: 24 jul. 2018.

VENTURA, Susana Ramos. As "pessoas" na obra de Antônio Torres. Navegações, Porto Alegre, v. 3, n. 2, p. 205-208, jul./dez. 2010.

Envio: $26 / 08 / 2019$

Aceite: 26/01/2020 